\title{
Quality Circle: A Methodology to Enhance the Plant Capacity through Why-Why Analysis
}

\author{
Janender Kumar \\ Department of Mechanical Engineering, \\ State Institute of Engineering \&Technology, Nilokheri, Karnal, Haryana, India. \\ E-mail: janyo_ishaan@yahoo.com \\ Krishan Kumar Kataria \\ Technical Education of Haryana, \\ State Board of Technical Education, Panchkula, Haryana, India. \\ E-mail: krishankumar.kataria@gmail.com \\ Sunil Luthra \\ Department of Mechanical Engineering, \\ Government Polytechnic, Jhajjar, Haryana, India. \\ Corresponding author: sunilluthra1977@gmail.com
}

(Received August 8, 2019; Accepted January 11, 2020)

\begin{abstract}
In the manufacturing firms, hospitals, banks, schools and research institutes etc., total customer satisfaction with products and services have very much importance and also necessary for their survival. Quality services and reducing wastages of all types are the primary need of every organisation. Quality Circle is (QC) is one of the techniques that can be utilised to solve industrial problems and can reduce the rejection level. In present paper, QC concept is implemented to solve wastage problem by taking a real case study of an automobile industry. The observed data was analysed through various problem solving techniques such as 80/20 rule and fishbone diagram etc. Finally, Why-Why analysis was carried out to identify the root cause of the problem and suggested actions to solve the problem. The following results were obtained: Gradually reduction in materials wastage minimises the rejection and hence reduces the overhead expenses of the firm. Further, QC helps in motivating employees to do their best for the organisation, which not only improves the productivity of the organisation, but also helps in discovering hidden talent and creative skill of the workforce. Finally, QC helps in developing the sense of belongingness towards organisations.
\end{abstract}

Keywords- Quality circle, Quality control tools, Problem solving techniques, Why-Why analysis, Automobile industry.

\section{Introduction}

In earlier days, during Second World War the whole industrial setups were destroyed of many countries. The major sufferer was Japan who came at back foot. In order to survive, the country was in search of excellence. They were trying for a method which rebuilt their industrial units and could improve quality of services and productivity in the industries. Then, the birth of Quality Circle (QC) has been taken place. Systematic implementation of QC leads the Japanese industries towards success (Dey et al., 1997; Shivagunde and Gupta, 1998). After a long period, it has now acceptance in India. The few companies which firstly launched the QC were Bharat Electronics Ltd, Bangalore and Bharat Heavy Electricals Ltd, Trichy in India (Prasanna and Desai, 2011).

Many organisations have successfully implemented this problem-solving tool to increase productivity and improve quality of product. Basically, QC is a group of peoples which work 
International Journal of Mathematical, Engineering and Management Sciences

Vol. 5, No. 3, 463-472, 2020

https://doi.org/10.33889/IJMEMS.2020.5.3.038

together like a team for solving work related problems. Everybody in team is free for given suggestions and ideas for betterment; he/she may be a worker or an engineer (Rungtusanatham et al., 2005). It's good initiative which is taken by Confederation of Indian Industries (CII) for motivating the Indian industries to use this concept and sort out their manufacturing problems.

The research work was different. Because, it did not observe during literature survey as the problem was new. The objectives of the research are to provide an overview of QC methodology and implementation in a real case example to enhance the plant capacity.

This paper is organised as: Section 2 provides a review on various QC studies reported in the literature. Section 3 briefly explains research methodology. Section 4 explains the real case analysis to enhance the plant capacity through reducing the waste problem. Finally, Conclusion of the research is provided with practical implications.

\section{Literature Review}

Lakshmi and Sucharitha (2019) discussed the impact of QC in the company. The growth of any company depends upon the positive efforts of workforce. To solve the problems of workplace QC plays a very important role. Not only it increases the motivation but also develops belongings towards company. During survey in the company, it concluded that most of the employees were not aware with this concept. So, awareness programs shall be organised for all.

Dhage (2019) suggested the implementation of QC in the educational institutions. The focus was on improving the quality of education by solving the problems of academicians as well as other assets of institutions.so that they can take the maximum utilisation of available resources in education.in a nutshell, quality education is the demand of global market. Prasana and Desai (2011) carried out a case study in petrochemical company using QC. Initially, the grease consumption was not uniform in the centrifuge, which is one of the components of a power plant. After implementation of QC, grease consumption optimised and it led to reduction in equipment failure. It results more productivity and also team members got motivated towards growth of the company.

Kaur (2019) explained how the QC led towards increasing productivity. The specified parameters can make the concept successful. These were complete involvement of each participant, problem should be chosen by quality control team members, management must have positive thinking for this concept, proper training must be given to members for problem solving tool, one higher authority, must be appoint as a mentor of the QC team. These all will make the study successful in the industry. Kumar and Mittal (2015) followed the methodology of QC in automobile parts manufacturing organisation. The step by step implementation of QC concept helped in reducing rejection quantity from 7000 pieces per day to zero and that was the huge achievement for the industry. Intangible benefits to QC members that they get motivated, increased belongings and become loyal for industry.

\section{Methodology: Quality Circle}

In a manufacturing organisation, the following basic elements comprise the structure of a QC (Prasanna and Desai, 2011).

i) Steering committee

ii) Co-ordinator 
International Journal of Mathematical, Engineering and Management Sciences

Vol. 5, No. 3, 463-472, 2020

https://doi.org/10.33889/IJMEMS.2020.5.3.038

iii) Facilitator

iv) Team leaders

vi) Team members.

The success of the QCs depends solely on the attitude of representatives from the top management and human resource development people (Guimaraes, 1997; Jha, 1997). Steering committee is headed by works manager which meets once in a month. The coordinator plays a positive role in QCs activities for the success of the efforts. The 24 meetings were planned in three months and successfully organised in fixed duration for the analysis. Facilitators from quality control department was also responsible for coordinating and directing the QC activities within an organisation and carries out such functions which would make the operations of QCs smooth, effective and self-sustainable. Leader of the QCs was chosen by the members among themselves. Since the members were the basic elements of the structure of QC and are the life blood of QC. It was the group of four to five members and they can be from different or same department. Some members were not the part of this activity but indirectly they were linked with circle members like production planning and control, industrial engineering and purchase department's personnel etc.

\subsection{Problem Solving Techniques}

QC generally uses the following basic approaches to identify and analyse problems:

i) Brainstorming session

ii) Data collection

iii) $80 / 20$ rule

iv) Cause and effect analysis

v) Quality control charts

vi) Why-why analysis.

\section{Case Analysis}

The current study was performed by choosing a problem, which was related with boring tool rejection at shop floor of a manufacturing unit (suspension system for 2 wheelers and 4 wheelers) in Gurugram (Haryana) by forming a QC. The production involves manufacturing of bottom cases of different models, one of the components of front fork (2-wheeler) in that area. The operation involves in producing the above product were blank process, oil seal process, boring process, axle hole process, drilling and finally tapping process. After that, washing and leakage testing of bottom cases were the last process.

The percentage wise breakup of consumable cost is given below and found that maximum rejection was during boring process. Hence, theme was selected to reduce boring tool consumption as $\%$ wise breakup of consumable costs shown in Table 1. 
International Journal of Mathematical, Engineering and Management Sciences

Vol. 5, No. 3, 463-472, 2020

https://doi.org/10.33889/IJMEMS.2020.5.3.038

Table 1. Percentage contribution of rejection due to various points

\begin{tabular}{|c|c|c|}
\hline S. No. & Consumable costs & \% contribution \\
\hline 1 & Boring Tool & 48 \\
\hline 2 & Cutting oil & 25.3 \\
\hline 3 & Drill \& inserts & 7.7 \\
\hline 4 & Maintenance costs & 6.8 \\
\hline 5 & Others & 12.2 \\
\hline
\end{tabular}

To reduce boring tool consumption as it contributes maximum $48 \%$ of total rejection in bottom case manufacturing area as shown in Figure 1.
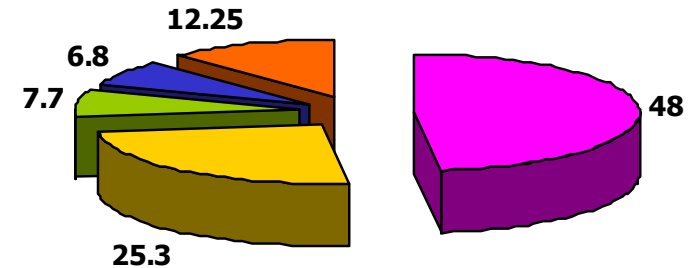

Figure1. Pie chart with breakup of consumable costs

\subsection{Deming Cycle}

PDCA (plan-do-check-act or plan-do-check-adjust) is a management approach, which is utilised for controlling and enhancement of manufacturing processes and products of a manufacturing unit The 4-meetings for planning activities like data collection and theme selection etc. 9- activities for root cause identification, facts analysis and others, 6-activities for data collection after implement of countermeasures and 5-activities for horizontal deployment of countermeasure on all similar machines. Deming cycle is shown in Figure 2.

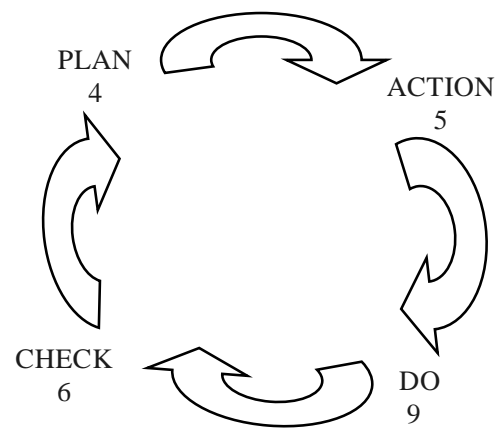

Planned meetings: 24

Actual meetings: 24

Figure 2. Deming cycle 
International Journal of Mathematical, Engineering and Management Sciences

Vol. 5, No. 3, 463-472, 2020

https://doi.org/10.33889/IJMEMS.2020.5.3.038

\subsubsection{Target Set}

$25 \%$ cost reduction i.e. cost/per piece 3.20 to 2.40 target was fixed.

\subsubsection{Flow Diagram (Sequence of Operations)}

The following processes were followed in making bottom case as shown in Figure 3.

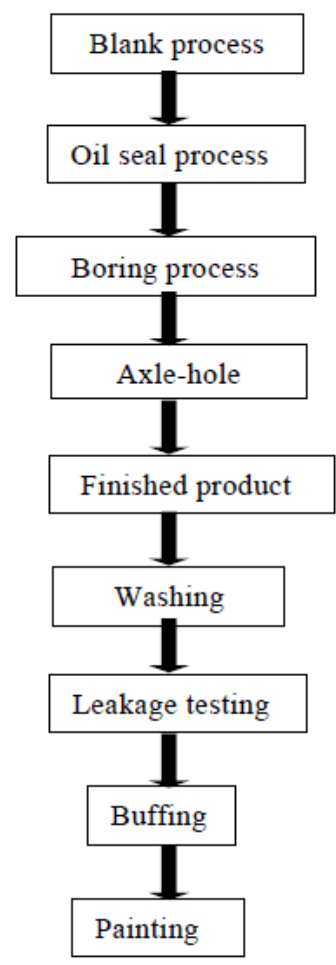

Figure 3. Sequences of bottom case making processes

\subsubsection{Cause and Effect Diagram}

The quality tool was utilised for analysing the root cause of the problem as shown in Figure 4.

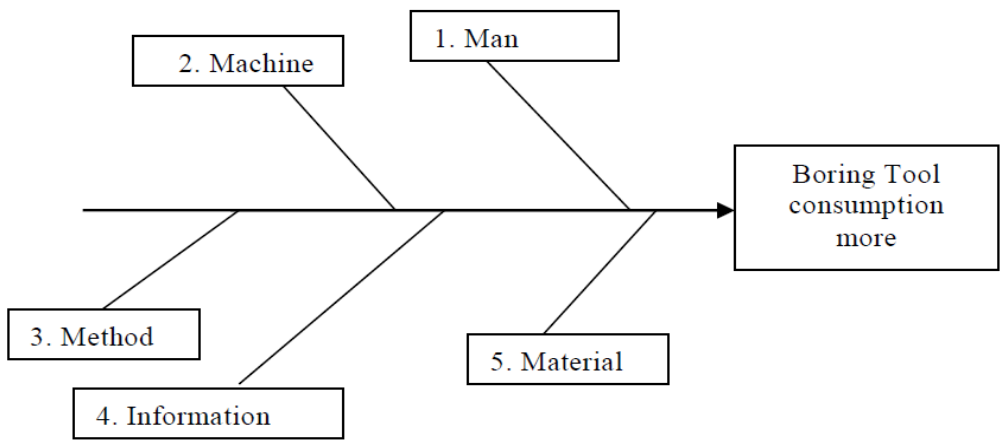

Figure 4. Cause and effect diagram for analysis 
International Journal of Mathematical, Engineering and Management Sciences

Vol. 5, No. 3, 463-472, 2020

https://doi.org/10.33889/IJMEMS.2020.5.3.038

The 4M's were analysed one by one to find the root cause as description is written below.

1. Man: - Negative attitude, lack of knowledge

2. Machine: -Wear out bush, oil pressure not good

3. Method: -lapping method not well, process not good

4. Material: -Boring and finishing tool under size

5. Information: - ok

\subsubsection{Temporary Countermeasure}

$100 \%$ inspection started in bottom case line to reduce more rejection in particular line immediately and ensured that it should not be move in two-wheeler assembly line. It was time consuming process but the activity was temporary.

\subsubsection{Permanent Countermeasures: Why-Why Analysis}

\subsubsection{Problem Number1}

KSPA model, rejection analysis conducted and found that 723 number of bottom cases were rejected due to shifting of centre during blank process and then analysed the reason with the help of Why-why analysis one of the problem-solving tool. Figure 5 shows bottom case with shifted axle hole.

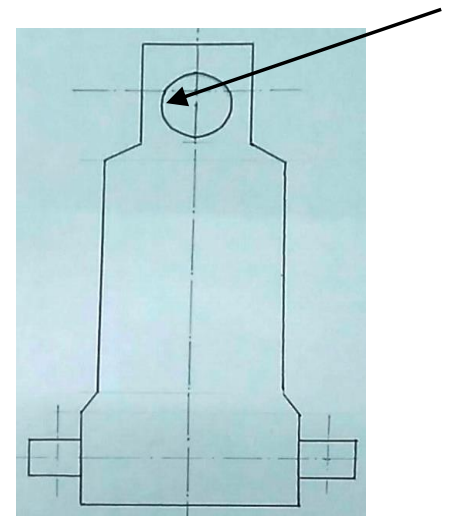

Figure 5. Bottom case with shifted axle hole

Why-Why analysis is an effective tool for solving work related problems. This method helps in maintaining the focus on the layer of symptoms which can lead to the root cause of a problem. That's the reason to use this method of depth analysis. In this analysis four questions were asked and answers are given for reaching near the root cause of problem (see Table 2). It found that burr on face of bottom case was creating problem during processing.

Table 2. Why-why analysis for axle hole shifting problem

\begin{tabular}{|c|c|c|c|}
\hline S. No. & Why-why analysis & Answer & Action taken \\
\hline 1. & $\begin{array}{l}\text { Why rejection more on } \\
\text { blank process }\end{array}$ & Center shifting & \\
\hline 2. & Why center shifting & Resting face uneven in casting & \\
\hline 3. & $\begin{array}{l}\text { Why resting face uneven } \\
\text { in casting }\end{array}$ & Manual filing at vendor end & \\
\hline 4. & $\begin{array}{l}\text { Why Manual filing at } \\
\text { vendor end }\end{array}$ & To remove burr from face & Atomisation done at vendor end \\
\hline
\end{tabular}


Bottom case was manufactured through casting process. Initially, it remains very rough and unsymmetrical at top surface. So, surface finish was done manually by doing filing. But it creates machining fault due to uneven top surface. Machining on face of bottom case was made as shown in Figure 7, instead of manual filing as shown below in Figure 6.

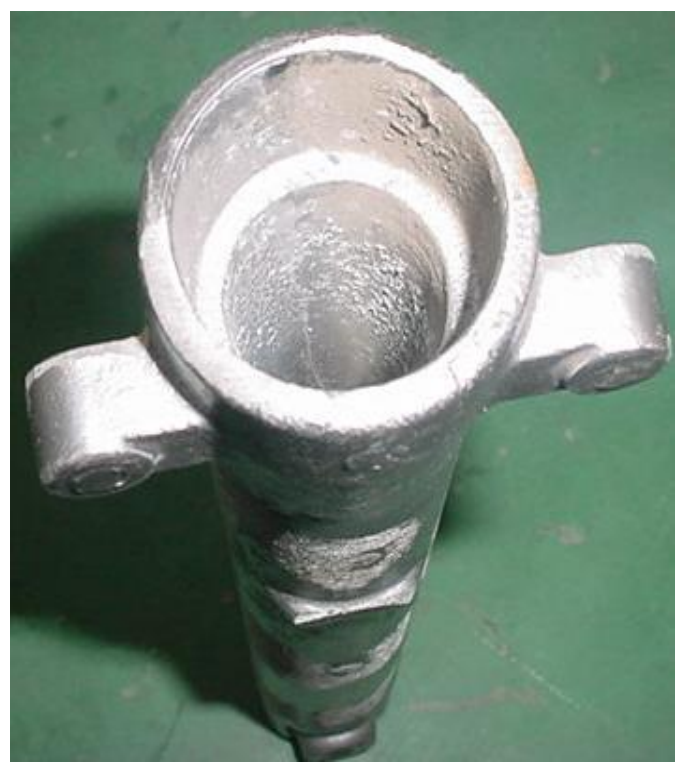

Figure 6. Bottom case before machining

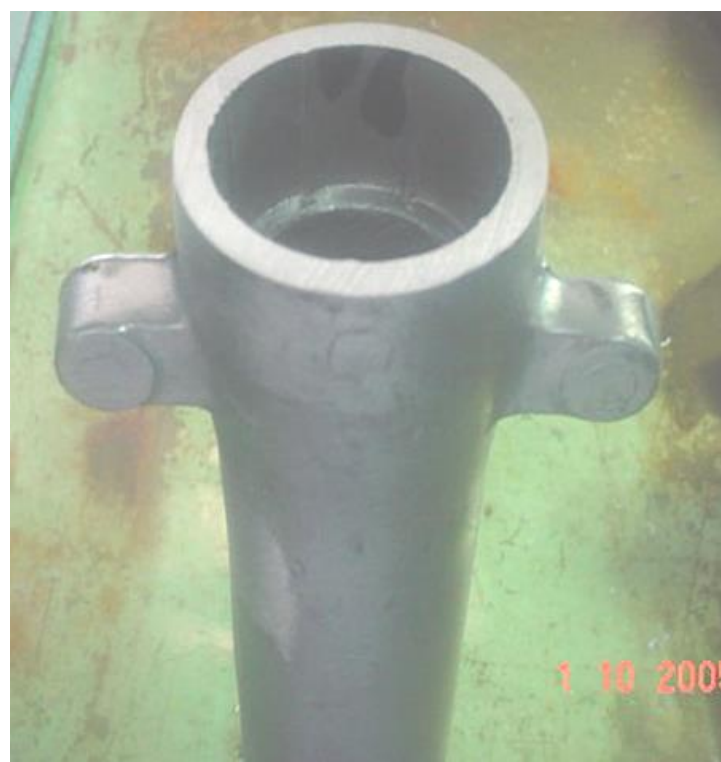

Figure 7. Bottom case after machining

Bottom case with shifted axle before implementation has been shown in Figure 8. After implementation of countermeasure first, rejection reduced from 94046 parts per million (ppm) to $70363 \mathrm{ppm}$ and production increased. Finally, hole shifting problem reduced as shown in Figure 9.

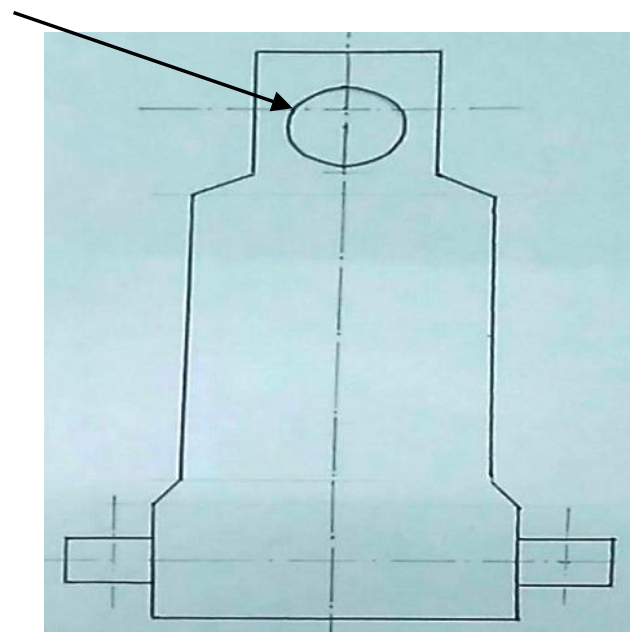

Figure 8 . Bottom case with shifted axle Before implementation

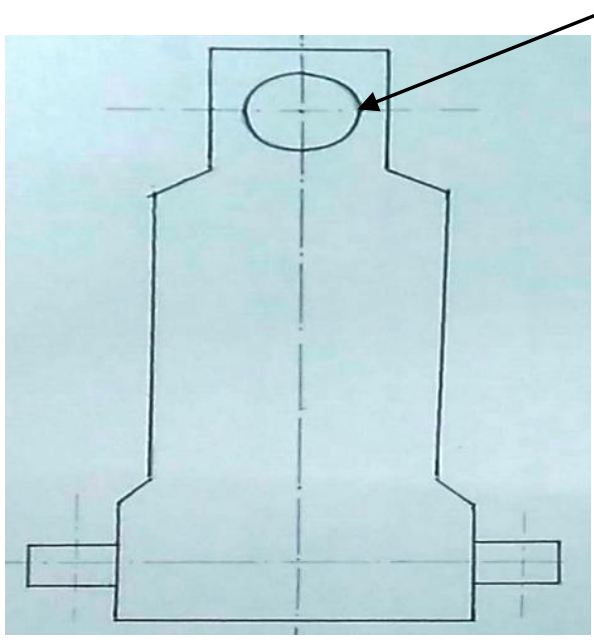

Figure 9. Bottom case with axle hole in centre After implementation 
International Journal of Mathematical, Engineering and Management Sciences

Vol. 5, No. 3, 463-472, 2020

https://doi.org/10.33889/IJMEMS.2020.5.3.038

\subsubsection{Problem Number 2}

Analysis for dimension $24.5 \mathrm{~mm}$ N.G., the distance from centre of bottom case to axle hole face. 1716 numbers were rejected during axle hole process because of this dimension parameter as shown in Figure 10.

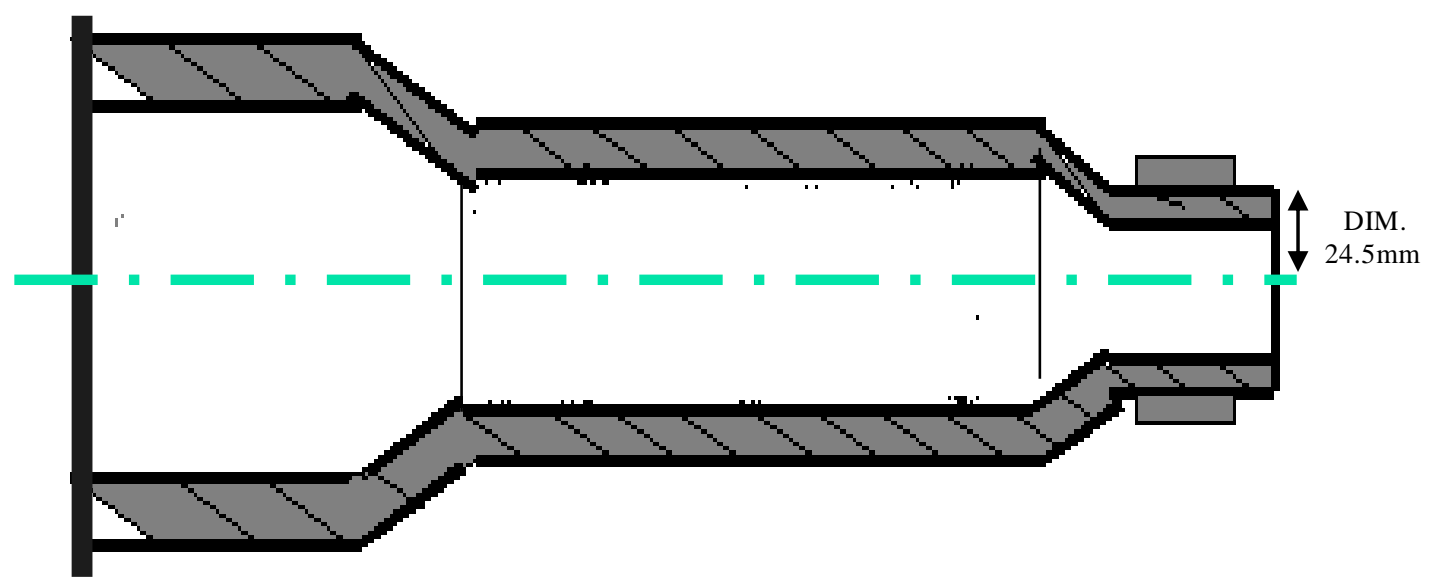

Figure 10. Dimension bottom case centre to axle- hole face

In this analysis four questions were asked and answers are given for reaching at the root cause of problem. Why-why analysis for variation in dim. $24.5 \mathrm{~mm}$ has been shown in Table 3. It found that variation in dimension was due to short life of tool as it develops built up edge on cutting edge.

Table 3. Why-why analysis for variation in dim. $24.5 \mathrm{~mm}$

\begin{tabular}{|c|c|c|c|}
\hline S. No. & Why-why analysis & Answer & Action taken \\
\hline 1. & $\begin{array}{c}\text { Why rejection more on axle hole } \\
\text { process }\end{array}$ & Variation in dimension 24.5 mm & $100 \%$ Checking \\
\hline 2. & Why variation in dimension 24.5 mm & Built up edge formation & \\
\hline 3. & Why built up edge formation & Aluminium welded on carbide tool's cutting edge & \\
\hline 4. & $\begin{array}{c}\text { Aluminium welded on carbide tool's } \\
\text { cutting edge }\end{array}$ & $\begin{array}{c}\text { Inherent property of aluminium to weld with } \\
\text { carbide }\end{array}$ & $\begin{array}{c}\text { Diamond insert } \\
\text { implemented }\end{array}$ \\
\hline
\end{tabular}

Carbide insert has been shown in Figure 11. In this, carbide insert was replaced by diamond insert on axle hole making machine. So, new tool introduced to reduce this variation as shown in Figure 12. 
International Journal of Mathematical, Engineering and Management Sciences

Vol. 5, No. 3, 463-472, 2020

https://doi.org/10.33889/IJMEMS.2020.5.3.038

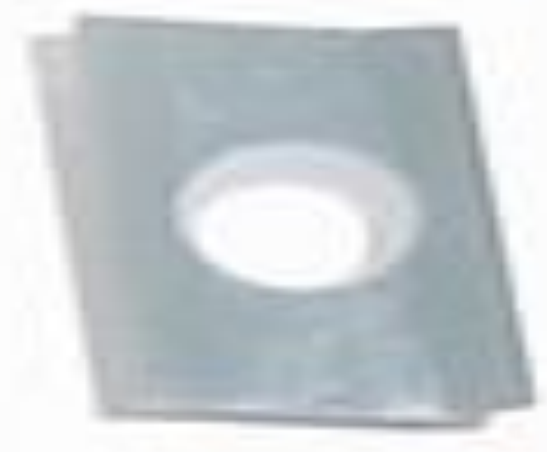

Figure 11. Carbide insert Before implementation

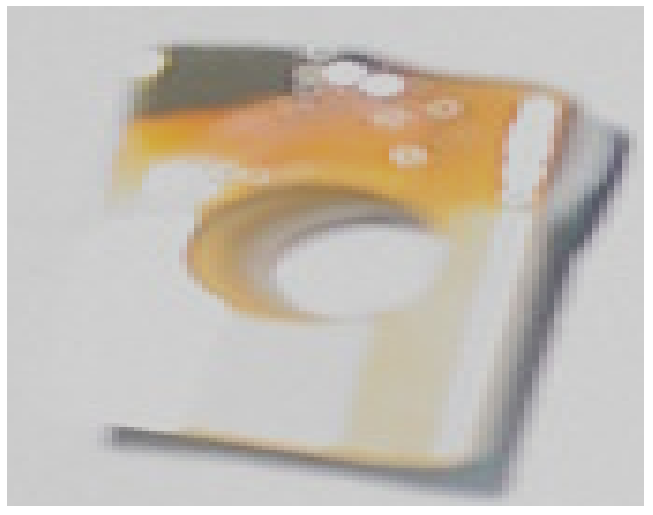

Figure 12. Diamond insert After implementation

After implementation of countermeasure second, results were awesome. Rejection reduced from $70363 \mathrm{ppm}$ to $32214 \mathrm{ppm}$ and this leads to drastic improvement in total production cost.

\section{Conclusion}

QC is a proven technique to identify, analyse and solve work-related problems. In our research, QC technique was implemented to solve wastage problem by taking a real case company situated in Gurugram. Overall, QC helped in solving the bottom case problem, one of the components of front fork (Suspension system). Rejection percentage was reduced drastically from $94046 \mathrm{ppm}$ to $32214 \mathrm{ppm}$ after implementation of Why-why analysis. In term of direct benefits, rejection reduction helped the firm in reducing production costs even more than $25 \%$ and overhead expenses as well as to enhance the production capacity.

In term of intangible benefits, QC helped in developing skills and moral between group members of QC, customer satisfaction and product reliability etc. The present work results could not be compared with the previous literature because any relative data with similar type of problem was not available. So, work carried out in this research can be utilised for solving the shop floor problems in various industries with this industrial engineering tool.

\section{Conflict of interest}

The authors declare that they have no conflict of interest to declare for this publication.

\section{Acknowledgements}

The authors would like to express their sincere thanks to the editor and anonymous reviewers for their time and valuable suggestions.

\section{References}

Dey, S.K., Banerjee, R.N., \& Ray, M.K. (1997). Genesis of quality circle with a case study. Journal of the Institution of Engineers (India) Mechanical Engineering Division, 78, 24-26. 
International Journal of Mathematical, Engineering and Management Sciences

Vol. 5, No. 3, 463-472, 2020

https://doi.org/10.33889/IJMEMS.2020.5.3.038

Dhage, S.N. (2019). Quality circle-a management tool for quality in higher education institutes. Aayushi International Interdisciplinary Research Journal, 6(5), 168-174.

Guimaraes, T. (1997). Assessing employee turnover intentions before/after TQM. International Journal of Quality and Reliability Management, 14(1), 46-63.

Jha, V. (1997). Quality circle implementation in Indian organization: an alternative viewpoint. Decision Journal, 24(1-4), 79-92.

Kaur, A. (2019). Quality circles the medium to enhance productivity levels. International Journal of Research in Engineering, Science and Management, 2(6), 199-203.

Kumar, N., \& Mittal, V. (2015). Quality circle implementation in industry in India-a case study. International Journal of Current Engineering and Technology, 5(1), 61-71.

Lakshmi, P.M., \& Sucharitha, P. (2019). Motivation and satisfaction through quality circles with reference to selected organization: an empirical study. International Journal of Multidisciplinary Research, 5(2), 33-40.

Prasanna, N.K.K., \& Desai, T.N. (2011). Quality circle implementation for maintenance management in petrochemical industry. Journal of Engineering Research and Studies, 2(1), 155-162.

Rungtusanatham, M., Forza, C., Koka, B.R., Salvador, F., \& Nie, W. (2005). TQM across multiple countries: convergence hypothesis versus national specificity arguments. Journal of Operations Management, 23(1), 43-63.

Shivagunde, R.B., \& Gupta, B.L. (1998). An innovative approach in technical education system for solving work related problems by quality circles. The Indian Journal of Technical Education, 21(1), 9. 